\title{
Artigos
}

\section{Acolhimento \& acesso de necessidades de saúde bucal e o agir profissional na Atenção Primária à Saúde}

\author{
User embracement \& access to oral health needs and professional practice \\ in Primary Health Care (abstract: p. 15)
}

Acogida y acceso de necesidades de salud bucal y el actuar profesional en la Atención Primaria de la Salud (resumen: p. 15)

\section{Cristine Maria Warmling(a) \\ <crismwarm@gmail.com> \\ Julio Baldisserotto ${ }^{(b)}$ \\ <jbaldisserotto@gmail.com>}

Evelise Tarouco da Rocha ${ }^{(\mathrm{c})}$

<evelise.rocha@sms.prefpoa.com.br>

\author{
(a) Programa de Pós-Graduação \\ Ensino na Saúde, Departamento de \\ Odontologia Preventiva e Social, \\ Universidade Federal do Rio Grande \\ do Sul (UFRGS). Rua Ramiro \\ Barcelos, 2492, Santa Cecilia. Porto \\ Alegre, RS, Brasil. 90035-004. \\ (b) Departamento de Odontologia \\ Preventiva e Social, UFRGS. Porto \\ Alegre, RS, Brasil. \\ (c) Secretaria Municipal de Saúde, \\ Prefeitura Municipal de Saúde. Porto \\ Alegre, RS, Brasil.
}

O objetivo do estudo é compreender o modo como Equipes de Saúde Bucal da Atenção Primária à Saúde articulam, no agir profissional, competências de acolhimento \& acesso de necessidades de saúde bucal. Trata-se de estudo de caso do tipo único e integrado com abordagem qualitativa. Um roteiro baseado no agir em competência apoiou a realização de nove grupos focais (16 cirurgiões-dentistas, cinco auxiliares, sete técnicos de saúde bucal e dois cirurgiões-dentistas residentes). Na implantação de protocolos de acolhimento \& acesso persiste a priorização de demandas espontâneas e de urgências dos usuários ao consultório odontológico. Práticas inovadoras de acolhimento \& acesso relacionamse com competências subjetivas dos trabalhadores no trabalho coletivo e na renormalização entre protocolos e realidades de saúde. Desenhos de educação permanente em Saúde devem propiciar o debate de valores entre instituições de ensino e serviços.

Palavras-chave: Acolhimento. Competência profissional. Prática profissional. Acesso aos serviços de saúde. Educação permanente. 


\section{Introdução}

Para reordenar o modelo de atenção à saúde bucal, alinhando-o ao preconizado pelo Sistema Único de Saúde (SUS), a Política Nacional de Saúde Bucal (PNSB) - Brasil Sorridente ${ }^{1}$ instituiu diretrizes programáticas com o objetivo de ampliar o acesso aos serviços odontológicos e qualificar o cuidado acolhedor, integral e centrado nas necessidades das pessoas ${ }^{2}$. Situa-se como uma das mais amplas políticas públicas odontológicas mundiais, porém análises epidemiológicas não demonstram tão evidentemente relaçóes entre o impacto da ampliação das Equipes de Saúde Bucal (ESB) na utilização (acesso) aos serviços odontológicos. Indícios apontam para a ideia de que a expansão do número de ESB, por si só, pode não garantir aumento no uso ou na qualidade dos serviços ${ }^{3,4}$.

Deslocando o conceito de acesso "do eixo de entrada dos serviços para o de cuidados recebidos” (p. S197), se o acesso diz respeito à forma como o usuário experimenta os serviços de saúde ou o modo como consome procedimentos, o acolhimento, para produzir a ampliação do acesso, está convocado a superar a naturalização da centralidade nas demandas terapêuticas características do modelo clínico-biomédico ${ }^{6,7}$. No caso da saúde bucal, isto significa ultrapassar as práticas discursivas centradas no elemento dentário, que marcam a constituição das competências profissionais ${ }^{8}$, pelo investimento na transformação das micropolíticas da gestão dos processos trabalho?

Os estudos sobre o processo de trabalho de ESB nos serviços públicos odontológicos, realizados entre os anos 1970 e 1990, em um contexto de altos índices de doença cárie e da necessidade de ampliar o acesso, centraram análises no âmbito da racionalização do trabalho: o aperfeiçoamento da organização e rendimento, a simplificação tecnológica e a utilização de profissionais auxiliares 5 . Recentemente, com as políticas de humanização relacionando o acesso às diretrizes de acolhimento ${ }^{6}$, houve uma valorização extra ao cotidiano dos processos de trabalho, voltando-se o interesse para a investigação das afinidades entre a ampliação do acesso e os aspectos subjetivos da relação tecnológica com o usuário ${ }^{7}$.

Resultados colhidos na avaliação das ESB realizada pelo Programa Nacional de Melhoria do Acesso e da Qualidade da Atenção Básica (PMAQ) destacam os processos de acolhimento e de vínculo nas práticas das equipes ${ }^{13}$. Fato que reafirma a tendência de que dimensões subjetivas, ou não tão facilmente padronizáveis, governam as competências dos trabalhadores de saúde bucal. Ou, o agir profissional que reconhece o caráter humano e o social como intrínsecos ao ato de cuidar tem se tornado preponderante na relação que se estabelece entre o profissional e o usuário.

Em outro sentido, verifica-se que o fenômeno atual de modernização da gestão de sistemas e modelos de planejamento em redes de saúde fundamenta-se nas necessidades de regulação do trabalho dos profissionais ${ }^{14}$. Nos processos de regulação destacamse os protocolos como parametrizadores das situaçóes de trabalho ${ }^{15}$. Com menos intensidade, as preocupaçóes voltam-se para como as condiçóes da organização do trabalho afetam o modo como os trabalhadores adquirem e utilizam as competências exigidas pelos protocolos ${ }^{16}$; ou para como o trabalhador, ao confrontar-se com situaçôes subjetivas e inusitadas no trabalho, investe seu próprio saber para solucionar problemas estabelecidos e recria competências nas situações de trabalho ${ }^{17}$. O desafio que se apresenta para os profissionais de saúde é o de desenvolver um agir em competência que seja capaz de articular, na tomada de decisão, o uso de protocolos 
como contexto singular e intersubjetivo que o momento exige ${ }^{18}$. Mas, como compreender sentidos, aparentemente tão desiguais, que se interpõem aos processos de trabalho nas equipes de saúde?

Em Porto Alegre, cenário do estudo, a cobertura populacional das ESB foi ampliada entre os anos de 2010 e 2014, passando de $17 \%$ para $32 \%$ da população ${ }^{19}$, porém, não houve modificação no padrão de organização do acesso da população à atenção odontológica. Em 2014, as práticas de acolhimento \& acesso à atenção em saúde bucal não diferiam muito das encontradas no ano de 2003, ainda anteriormente à implantação da própria PNSB, quando se constatava dificuldade de acesso à consulta odontológica que ocorria, sobretudo, pela procura de vagas por meio de filas organizadas nas primeiras horas da manhã antes da abertura das unidades de saúde ${ }^{20}$. A dificuldade na organização do acesso dos cidadãos aos serviços de saúde tornou-se um desafio ao planejamento em saúde bucal. A gestão municipal adotou o acolhimento, estratégia da Política Nacional de Humanização $(\mathrm{PNH})^{11}$, para o processo de reorganização da forma de acesso do cidadão à APS do município ${ }^{19}$. A Área Técnica de Saúde Bucal realizou reunióes com as equipes de saúde nas oito gerências distritais do município para implantar novas formas de acolhimento. Houve ampla participação dos profissionais de saúde bucal de todas as regiốes ${ }^{21}$.

O cenário descrito interpôs questionamentos que guiaram a pesquisa: Como as ESB integram, aos protocolos parametrizadores da atenção em saúde bucal, as singularidades dos usuários no dinâmico cotidiano do trabalho em saúde? $\mathrm{Ou}$, como articulam dimensões da competência profissional, tais como, o acolhimento e a organização do acesso das necessidades de saúde bucal? E, ainda, até que ponto o trabalho das ESB se constitui como colaborativo e espaços institucionais coletivos promovem problematizaçóes dos dilemas que se apresentam ao exercício profissional?

Nesse contexto social, político e técnico é que emerge o objetivo principal do estudo: compreender o modo como ESB, que atuam na APS do município de Porto Alegre/RS, articulam, no próprio agir profissional, dimensôes subjetivas das competências para enfrentarem problemas do cotidiano contemporâneo da produção do cuidado na saúde bucal, por exemplo: a questão do acolhimento \& acesso das necessidades de saúde bucal dos usuários.

\section{Metodologia}

Trata-se de um estudo de caso do tipo único e integrado com múltiplas unidades de análise e abordagem metodológica qualitativa ${ }^{22,23}$. O objetivo foi alcançar dimensóes subjetivas dos processos de trabalho das equipes de saúde bucal que transcendem indicadores e expressóes numéricas comumente utilizadas nos processos avaliativos.

No período entre janeiro a maio de 2014 foram realizados nove grupos focais: oito com ESB em oito Unidades Básicas de Saúde (UBS) de cinco distritos sanitários do município de Porto Alegre (12 cirurgióes-dentistas, cinco auxiliares, seis técnicos de saúde bucal e dois cirurgióes-dentistas residentes) e um grupo focal com membros do Colegiado Gestor de Saúde Bucal do município (quatro cirurgiôes-dentistas e um técnico de saúde bucal). O critério de escolha foi incluir ESB de diferentes distritos e realidades sanitárias, assim como uma unidade gestora central do município. Os grupos focais foram gravados, filmados e transcritos para serem analisados. O grupo focal foi 
conduzido por um coordenador e acompanhado de um relator, com o auxílio de um roteiro de pesquisa baseado nos ingredientes do agir em competência de Schwartz e Durrive $^{24}$ (Quadro 1). A pesquisadora principal, cirurgiã-dentista da equipe de gestão municipal, produziu, ao longo do estudo, registros de diário de $\mathrm{campo}^{25}$, na medida em que possuía visão privilegiada de aproximação ao contexto do agir profissional das ESB em relação às açốes de acolhimento \& acesso na produção de cuidado na saúde.

Quadro 1. Roteiro ingredientes para a produção do cuidado na saúde bucal baseado na teoria sobre o agir em competência de Schwartz (2010) ${ }^{18}$.

\begin{tabular}{|c|c|c|}
\hline $\begin{array}{l}\text { Dimensões para a produção do cuidado } \\
\text { na saúde bucal }\end{array}$ & Objetivos & Norteador \\
\hline $\begin{array}{c}\text { INGREDIENTE 1: } \\
\text { PROTOCOLOS } \\
\text { O relativo domínio de algo codificado }\end{array}$ & $\begin{array}{l}\text { Objetivo 1: Identificar protocolos para o cuidado } \\
\text { na saúde bucal utilizados. }\end{array}$ & $\begin{array}{l}\text { Falar sobre os protocolos mais usados na } \\
\text { produção do cuidado na saúde bucal. }\end{array}$ \\
\hline $\begin{array}{c}\text { INGREDIENTE 2: } \\
\text { CONHECIMENTO DA REALIDADE } \\
\text { O relativo domínio de algo não codificado }\end{array}$ & $\begin{array}{l}\text { Objetivo } 2 \text { : Identificar singularidades da } \\
\text { realidade do trabalho. }\end{array}$ & $\begin{array}{l}\text { Falar sobre as realidades que contextualizam } \\
\text { o trabalho na saúde bucal. }\end{array}$ \\
\hline $\begin{array}{c}\text { INGREDIENTE 3: } \\
\text { RENORMALIZAÇÃO } \\
\text { O domínio da decisão pertinente no } \\
\text { momento certo }\end{array}$ & $\begin{array}{l}\text { Objetivo 3: Identificar como o profissional } \\
\text { renormaliza protocolos conforme cada } \\
\text { situação. }\end{array}$ & $\begin{array}{c}\text { Falar sobre a articulação entre o que } \\
\text { preconizam os protocolos e as realidades de } \\
\text { trabalho. }\end{array}$ \\
\hline $\begin{array}{l}\text { INGREDIENTE 4: } \\
\text { "O USO DE SI POR SI" }\end{array}$ & Objetivo 4: Identificar a motivação das ESB & $\begin{array}{l}\text { Falar sobre a motivação para trabalhar com } \\
\text { a saúde bucal no SUS. }\end{array}$ \\
\hline $\begin{array}{l}\text { INGREDIENTE 5: } \\
\text { DEBATE DE VALORES }\end{array}$ & $\begin{array}{l}\text { Objetivo 5: Identificar o debate de normas } \\
\text { impostas e instituídas na atividade de trabalho. }\end{array}$ & $\begin{array}{l}\text { As dinâmicas do trabalho na APS permitem a } \\
\text { renegociação de valores e normas. }\end{array}$ \\
\hline $\begin{array}{l}\text { INGREDIENTE 6: } \\
\text { TRABALHO EM EQUIPE } \\
\text { A sinergia com o coletivo }\end{array}$ & $\begin{array}{c}\text { Objetivo 6: Identificar a experiência do trabalho } \\
\text { em equipe }\end{array}$ & $\begin{array}{l}\text { Descreva o trabalho em equipe para o } \\
\text { cuidado em saúde bucal. }\end{array}$ \\
\hline
\end{tabular}

A escolha da técnica do grupo focal privilegiou a observação e registro de experiências e reações dos indivíduos participantes. Objetivou-se o diálogo em profundidade com um nível maior de trocas entre os participantes. As discussóes, confrontos e discordâncias procuraram ser respeitadas. Define-se o caráter teórico de interação dos participantes e produção de dados como de perspectiva social construtivista ${ }^{26,27}$.

Para a organização e análise dos dados produzidos utilizou-se o software NVivo versão 10 para Windows. A síntese cruzada das práticas discursivas nas múltiplas unidades de análise foi realizada fundamentando-se na teoria do agir profissional ${ }^{24}$. O sentido alcançado não é traduzido, mas produzido articulando-se o linguístico com o social e o histórico, pois não se apresenta como representação natural do mundo social e é produzido nas relaçốes que os discursos estabelecem e colocam em funcionamento. Compreende-se que discursos são práticas que atravessam e orientam a atuação das ESB, produzem efeitos e condiçóes de possibilidade dos seus processos de trabalho ${ }^{28}$.

O projeto de pesquisa foi submetido a análise ética por meio da Plataforma Brasil, possuindo parecer consubstanciado aprovado com o número CAAE: 15738613.1.0000.5347. Apenas foram considerados participantes da pesquisa os participantes que assinaram o Termo de Consentimento Livre e Esclarecido (TCLE). 


\section{Resultados e discussão}

\section{Práticas inovadoras de acolhimento \& acesso de necessidades de saúde bucal}

Há um conjunto de propostas descrito na PNSB desafiando os processos de trabalho das ESB para inovarem nos processos acolhedores das necessidades de saúde bucal das pessoas: basear-se no trabalho integrado e interprofissional, em processos de territorialização, na responsabilização profissional, na ampliação na clínica e autonomia do usuário, na criação de vínculo e na educação permanente em Saúde, etc. ${ }^{29}$. Entraves para a incorporação dessas práticas inovadoras podem estar relacionados com a persistência em dinâmicas de organização tecnológica e da assistência odontológica tradicionalmente centradas na demanda por procedimentos, e não na pessoa.

As estratégias de acolhimento emergiram tardiamente nas propostas de reprogramação das políticas públicas interligadas com a criação de dispositivos e modos de repensar e mudar não apenas a recepção das pessoas, mas o acesso às necessidades de saúde ${ }^{30}$. Os princípios da universalidade de acesso, do desenvolvimento de práticas multiprofissionais e da qualificação das relaçôes entre usuários e trabalhadores direcionam as propostas de implantação de modelos de acolhimento ${ }^{31}$. Observa-se certo caráter redutor na compreensão do acolhimento quando limitado "a açôes de triagem na porta de entrada, ou mesmo as técnicas de recepção do usuário e suas demandas, sem interferir na gestão dos processos de trabalho"13 (p. 153). O acolhimento trata de um processo relacional de encontro entre sujeitos e tecnologias, ou seja, o reconhecimento das lógicas da saúde do usuário para a definição tecnológica do projeto terapêutico.

A Figura 1 apresenta resultados principais produzidos pelo estudo representados no esquema teórico das dinâmicas dos ingredientes do agir em competência ${ }^{24}$. As iniciativas de reorganização do acesso à saúde bucal ocorrem por meio de gerenciamentos do acolhimento, mas com baixa capacidade de renormalização entre os protocolos (saberes investidos) e as singularidades das realidades de trabalho (saberes instituídos). As ESB não produzam renormalizaçóes potentes para instituir processos e práticas de inovadores.

Nas práticas discursivas profissionais das ESB, o ato de acolher as necessidades de saúde bucal está centrado em promover acesso ao atendimento odontológico. Apresenta-se como um modo de atendimento à demanda espontânea de urgências, associado ao agendamento tradicional por meio da distribuição de fichas individuais, ou por meio da organização de grupos (sala de identificação de necessidades). $\mathrm{O}$ ato de acolher necessidades de saúde bucal segue destacando-se pela valorização da conduta terapêutica fundamentada na definição de número de vagas para o atendimento de procedimentos odontológicos necessários para a conclusão de planos de tratamento. Os entraves para realizar o acolhimento estão relacionados à própria dinâmica tradicional de funcionamento do atendimento odontológico ou "fundamentado no modelo clínico-biomédico e no atendimento baseado no modelo queixa-conduta como forma de triagem"12 (p. 193). 


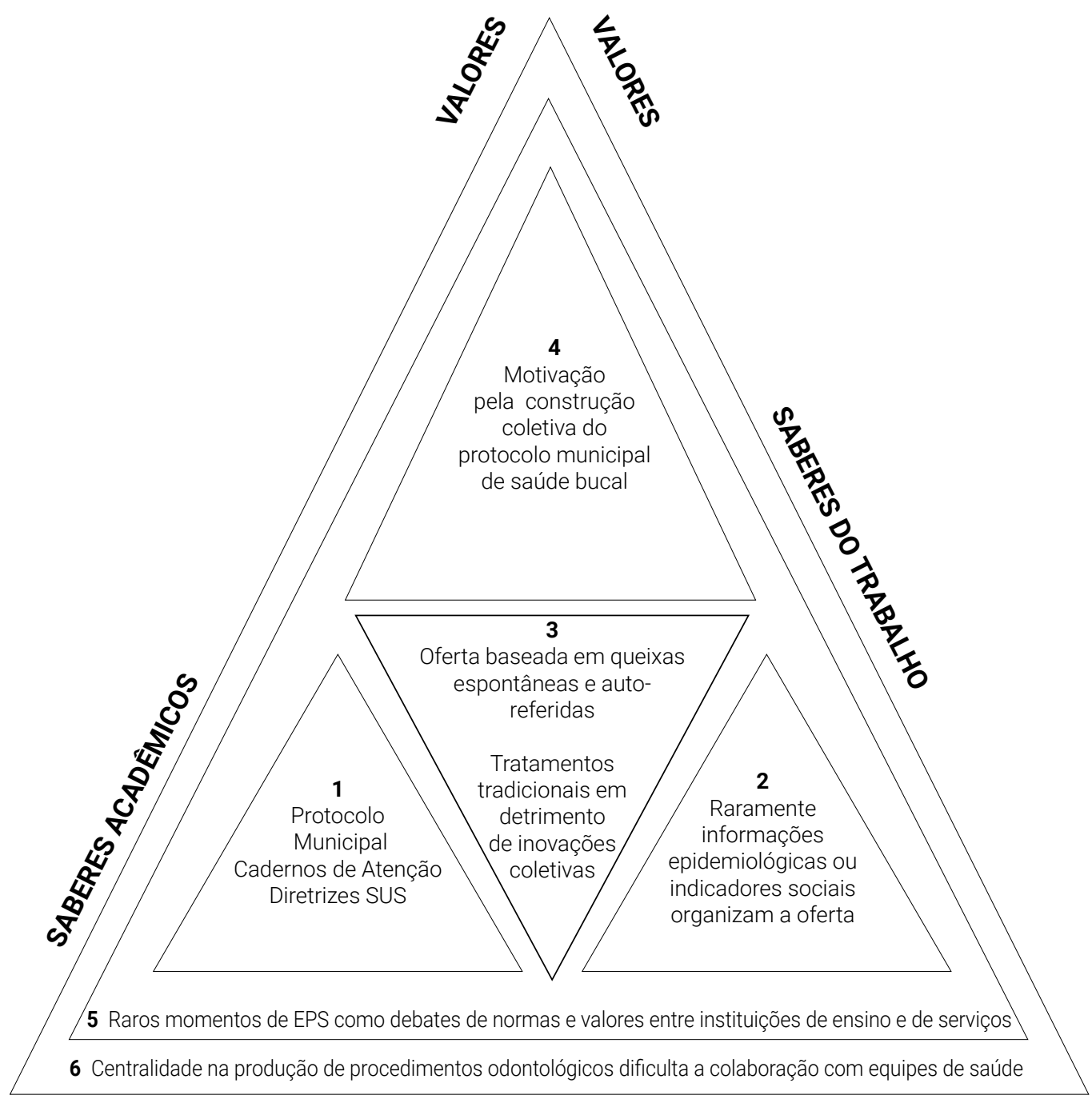

* Compreende-se: 1 - protocolos, 2 - realidade, 3 - renormalizações, 4 - motivação, 5 - debate de valores e 6 - equipe (ver Quadro 1 - com definições teóricas)

Figura 1. A tripolaridade da atividade humana (saber-atividade-valor) e os ingredientes do agir em competência no esquema de Durrive ${ }^{18}$ (p. 213) representados nas práticas discursivas das ESB analisadas*.

"Prefiro que as pessoas tenham uma dificuldade de acesso que eu acho horrível, mas que tenham todo o tratamento garantido, do que isso vire um pronto atendimento. Abrir a agenda e as pessoas têm um retorno muito longo, as pessoas vão abandonar o tratamento, elas vão vir só quando elas têm dor.” (T03)

“Em uma reunião, nos colocamos -”a gente deixa uma agenda lá na frente, o agente de saúde que fica na recepção e agenda”. Mas, eu preferi que não fosse assim pois vai atrapalhar e eu prefiro ver quem é o paciente que está agendado, até para cobrar ele se ele for faltoso, para saber qual procedimento vai fazer. Aí ficou decidido assim.” (T05) 
"Nós trabalhamos com agenda de papel. Todo mundo que é atendido daqui de dentro (consultório odontológico) já sai com consulta marcada [...] E se a gente, por exemplo, deixar a agenda aberta lá na frente e ela simplesmente marcar, daqui a pouco marcou dez exodontias na mesma manhã. Então, na verdade é um pouquinho diferente da agenda do médico e da enfermeira.” (T07)

"A gente viu que isso estava prejudicando um pouco. Então, 50\% das consultas ofertadas são para os pacientes que estão em atendimento, para que possam ter um tratamento contínuo mais rápido. E os outros $50 \%$ são os pacientes que vêm pela primeira vez, ou que faltaram.” (T06)

A agenda superlotada é um problema recorrente nas práticas discursivas. A centralidade no acolhimento da demanda de quem procura por atendimento odontológico e a insuficiência de ESB para atender a demanda geram sobrecarga de trabalho. Um fato que desestimula os profissionais frente às estratégias de reorganização do acolhimento \& acesso na saúde bucal ou a busca ativa de grupos com maior vulnerabilidade.

"A ideia era direcionar as consultas no acolhimento, se fosse demanda agendada, ou demanda imediata, dependendo da necessidade do paciente. Só que na prática não funcionou, porque é muita demanda e a ideia não é invadir além de um mês de agenda.” (T02)

"A demanda é grande, tem muitas pessoas precisando de atendimento. A gente não tem condiçốes de deixar uma agenda aberta. A pessoa vai lá, marca a consulta hoje, e o retorno dela vai ser para daqui a dois meses. A pessoa chega lá hoje para marcar para daqui três meses. Então, eu não vejo lógica nisso. As pessoas que procuram, são aquelas pessoas que precisam. É difícil tu chegar a uma pessoa e dizer "tu não tens necessidade".” (T03)

Mas, como articular demanda e oferta no cuidado em saúde bucal? Oferta relaciona-se à disponibilidade, a tipo e a quantidade de serviços oferecidos; a demanda, por sua vez, refere-se ao motivo da procura do usuário pela atenção à saúde ${ }^{32}$. O modelo tradicional de atendimento odontológico centrado no procedimento dentário determina os processos decisórios que se estabelecem na relação entre o que se oferta e o que se demanda. A prática odontológica perpetua tópicos que ditam as relaçóes e decisôes terapêuticas: o reducionismo das questôes humanas e sociais no momento do encontro terapêutico e a hipervalorização do biológico na produção do cuidado de saúde bucal ${ }^{33}$.

Pode-se observar, nas práticas discursivas profissionais das ESB, que, na relação entre oferta e demanda, é a demanda que se modela à oferta. Os processos de trabalho na saúde (objetos sócio-históricos), ao criarem produtos para satisfazer necessidades de saúde dos usuários, criam, no mesmo movimento, as necessidades dos usuários pelos produtos que criaram ${ }^{34}$. Neste sentido, o acolhimento produzido pelas ESB não se caracteriza como um espaço de inovação de produção de tecnologias de saúde bucal apropriadas. No diálogo e nas negociações entre profissionais e usuários em que 
o maior desafio seria compreender a demanda para o replanejamento do serviço, não prevalece a incorporação de novos conhecimentos/produtos ou objetos. A realidade do processo de trabalho das ESB caracteriza-se como "uma escuta clínica, focalizada nas queixas e na intervenção pontual, pouco resolutiva e não construtora de vínculo, contribuindo pouco para a autonomização do usuário" ${ }^{35}$ (p. 150).

Se, nas diretrizes da organização do trabalho na APS, está intrínseco o reconhecimento das condições de vida, de saúde e de doença da população, as práticas discursivas do agir profissional das ESB analisadas centram-se nas demandas referidas dos usuários quando chegam no consultório odontológico. Usam raramente informações epidemiológicas ou indicadores sociais para diagnóstico da realidade de saúde em que atuam. Isto sugere que organizam a oferta, prioritariamente, conforme a demanda espontânea por atendimento. O problema no modelo de práticas pautado quase que exclusivamente no atendimento às queixas autorreferidas dos usuários que buscam as unidades de saúde é a sua organização excludente e que prioriza grupos específicos em detrimento da maioria da população.

"Números de primeiras consultas que eu fiz está proporcional ao número de tratamentos concluídos. A gente está conseguindo ter essa proporção. É isso [...] claro que vai do interesse da pessoa, também, mas é isso que eu digo. Se eu tenho $80 \%$ de atendimento na cadeira, atendendo um número superior de pacientes do que é recomendado, só se de noite, no final de semana, eu iria estudar os indicadores, para ver qual é a meta do município.” (T06)

A incorporação de práticas inovadoras de acolhimento na saúde bucal não se relaciona diretamente ao aumento do número de profissionais nas ESB ou ao investimento em melhores condições de trabalho por tratarem-se de transformaçóes nas competências subjetivas dos trabalhadores. A inovação, enquanto incorporação de novos conhecimentos, demanda outros conceitos de produção de cuidado e processos de trabalho, outras formas de pensar e problematizar os processos de saúde e doença para a produção de clínica inovadora. Dependerá da constituição de outros sujeitos com outras subjetividades e outras necessidades?

\section{0 trabalho coletivo no centro do agir profissional e da educação permanente em Saúde}

Nas práticas discursivas sobre a organização do processo de produção do cuidado em saúde bucal das ESB analisadas é especialmente referido o uso do "Protocolo de Atenção em Saúde Bucal de Porto Alegre - organização da rede e fluxos de atendimento" ${ }^{36} \mathrm{e}$ dos protocolos de atenção básica contidos nos Cadernos de Atenção Básica $\square$ Saúde Bucal ${ }^{37}$. Diretrizes e leis do SUS também direcionam o cotidiano de trabalho na saúde bucal.

O domínio dos protocolos trata-se de um dos ingredientes basilares da competência profissional. Dominar um conhecimento técnico adquirido previamente é imprescindível ao agir profissional com competência frente às situações de trabalho. Mas, o que é prescrito para o trabalhador desempenhar pode se distanciar do que ele vivencia na realidade. A dinamicidade da atividade humana prejudica a capacidade de 
antever as realidades de trabalho. As regras que orientam os processos de trabalho terão de ser constantemente transformadas (ou renormalizadas) por meio do uso de saberes e práticas dos próprios trabalhadores. Os trabalhadores mobilizam com intensidade semelhante tanto saberes próprios, quanto saberes já constituídos que orientam as práticas $^{18}$.

O "Protocolo de Atenção em Saúde Bucal de Porto Alegre - organização da rede e fluxos de atendimento" ${ }^{36}$ foi produzido com a participação de um coletivo de trabalhadores da SMS, com o objetivo de reorganizar o processo de trabalho das ESB, seus fluxos e modalidades de acolhimento e de acesso dos usuários. Porém, ao traçar diretrizes gerais para a organização do cuidado em saúde bucal não significa que o protocolo apresente respostas para todas as situaçóes do cotidiano do trabalho. As experiências dos profissionais também orientam a organização do processo de trabalho.

"Muitos dos nossos protocolos a gente procura organizar dentro da nossa equipe, como se fosse uma pactuação interna nossa.” (T12)

"Acho que a gente muda sim [os protocolos], por exemplo, agora a gente resolveu fazer o acolhimento.” (T10)

As práticas discursivas analisadas atribuem, às constantes mudanças na gestão dos serviços, uma limitação para a continuidade das açóes e projetos propostos pelos coletivos para a organização das políticas de saúde bucal do município. Em contrapartida, o Protocolo de Atenção em Saúde Bucal de Porto Alegre fortaleceria a sistematização das diretrizes pactuadas coletivamente. Pode ser compreendido como fio condutor da motivação para o trabalho coletivo ou para a vontade de fazer parte de um projeto municipal de saúde bucal para a população. Produz pertencimento aos processos de mudanças. "Trabalhar é bem mais do que produzir com a ajuda de técnicas, mas sim viver um projeto coletivo"18 (p. 100). Há uma necessidade humana de, ao trabalhar, concretizar projetos e experiências, solidificá-los nas instituiçóes em que se atua.

"As pessoas têm que ter essa segurança, que esse vai ser o trabalho, essa é a forma correta de agir [...] isso evita aquilo que a gente sempre fica com medo: que tem um projeto tal que é de tal pessoa que entrou agora na Área Técnica de Saúde Bucal [...] Aí vai todo mundo, corre pro tal do projeto mas já pensando assim: puxa, esse projeto daqui a três meses pode estar na gaveta.” (T02)

"Se o profissional não se sentir parte disso, a chance dele rejeitar esse protocolo é muito alta [...] que a gente faça com que toda equipe se sinta parte dessa construção para que não seja assim, mais um gestor que vem com uma ideia nova." (T01)

A importância do controle social na determinação das condiçốes de acesso à atenção em saúde bucal é reconhecida nas práticas discursivas das ESB, porém não costumam participar dos espaços de controle social. É raro o envolvimento comunitário ou coletivo na organização do acolhimento \& acesso. Isso tem ocorrido 
prioritariamente por demandas próprias ou dos usuários que conseguem acessar os serviços de saúde, e nem tanto pelo reconhecimento das necessidades coletivas de saúde nas comunidades onde atuam. A inovação nas tecnologias de acolhimento \& acesso às necessidades de saúde envolve problematizaçóes sobre as relaçóes que se estabelecem entre poderes e saberes que definem as práticas de saúde ${ }^{38}$. O problema em pautar-se quase que exclusivamente no atendimento às queixas individuais e autorreferidas dos usuários que buscam as unidades de saúde é a organização de práticas que priorizam tratamentos tradicionais em detrimento de processos e inovaçôes coletivas.

"Logo no início, as pessoas continuavam vindo na segunda-feira por um hábito e aí foi passado já em conselho local como estava funcionando o agendamento odontológico. Mas são poucos os que participam do conselho local [...] Eu não tenho informação de que o usuário tenha brigado, ou que tenha se sentido prejudicado, descontente pela forma de agendamento. A única coisa que a gente vê bastante é que ele não quer esperar. 'Ah, eu quero agendar'.” (T06)

O acolhimento das necessidades de saúde bucal nos contextos e cenários estudados é compreendido, nas práticas discursivas das ESB, como de responsabilidade do cirurgião-dentista. A existência de ESB nos ambientes de trabalho na APS não é suficiente para a constituição do trabalho coletivo. A centralidade na produção de procedimentos clínicos odontológicos dificulta a colaboração. O modo tradicional de formação do cirurgião-dentista, fundamentado em práticas uniprofissionais e extremamente autonomizadas, reforça o isolamento da prática de saúde bucal, inclusive, em propostas de atenção que visam promover a integralidade do cuidado em saúde.

"A resistência maior de integrar a saúde bucal no acolhimento é da equipe [de saúde], pela demanda reprimida enorme [de saúde bucal].” (Diário de Campo)

"Acho que são duas questôes, como a gente vê e como a equipe nos vê. Porque [...] eu achava que a gente estava muito integrada, na questão do acolhimento ser único, de a gente estar sempre trocando com o pessoal técnico [...] mas quando eu peguei o relatório da residente da enfermagem eu vi que ela tinha uma outra visão da gente. [...] Ela disse que a odontologia era muito isolada, que a odontologia ficava aqui no final do corredor, que a gente não discutia casos. [...] acho que tem muito ainda para conquistar [...] mas a gente se enxerga integrado. Mas eu não sei te dizer se a equipe nos enxerga tão integrado assim. Depois que eu li aquele relatório eu fiquei em dúvida.” (T05)

"Quando estamos discutindo temas de interesse comum nas reuniões, todos estão presentes e participam, quando pedimos licença para falar de alguma coisa da odontologia, uns se levantam, outros vão para o computador, a reunião esvazia e nós permanecemos discutindo sozinhos.” (Diário de Campo)

O redescobrimento do valor subjetivo do trabalho está relacionado à compreensão de como o próprio trabalho se insere no trabalho de outros trabalhadores e na vida em 
sociedade. A criação de laços entre os trabalhadores, o compartilhamento de valores e o uso que cada um faz de si em função do coletivo constitui o trabalho em equipe. $\mathrm{O}$ trabalhador ao reconhecer que está inserido no trabalho coletivo partilha, ao longo do tempo, regras informais de funcionamento ${ }^{39}$.

Nas práticas discursivas das ESB analisadas, as expectativas dos profissionais em relação à qualificação profissional centram-se em capacitaçóes formais de cursos ministrados por especialistas. Os encontros mensais das equipes de saúde bucal nas gerências distritais não são considerados pelas ESB como momentos de educação permanente, pois lá discute-se «mais essas questóes de processo de trabalho mesmo (T05)". Na demanda por capacitaçóes o protagonismo das ESB e a problematização dos processos de trabalho não são tão reconhecidos. Não é comum práticas discursivas sobre educação permanente nas unidades de saúde e, quando há reunióes de equipe com educação permanente, não ocorrem de forma regular ou sistemática, apesar de as políticas públicas de educação permanente na saúde reconhecerem a insuficiência dos treinamentos formais e teóricos para o desenvolvimento de competências.

"Eu acho que antes era melhor [...] todo mês a gente tinha um curso lá na SMS [...] com professores da faculdade de todas áreas.” (T10)

"A universidade poderia nos dar uma contrapartida melhor nessa parte de educação permanente.” (T04)

Espaços de educação permanente como momentos de debates de normas e valores entre instituiçóes de ensino e serviços de saúde, colocam em diálogo as necessidades das partes envolvidas - trabalhadores, estudantes, serviços, instituições de ensino, gestão, usuários e controle social. O cotidiano de trabalho valorizado nas propostas de educação permanente permite o ensaio do enfrentamento de situaçôes reais e complexas, segundo padróes prévios socialmente definidos, como, por exemplo, as diretrizes do SUS e os protocolos de saúde bucal. No desenvolvimento de capacidades e competências, permite-se a reconstrução da clínica perpassada por um processo de problematização da própria prática profissional e da realidade das situaçóes de trabalho.

\section{Considerações finais}

As ESB que participaram do estudo apresentam dificuldades em articular nos processos de trabalho inovaçóes de acolhimento \& acesso das necessidades de saúde bucal. Justificam-se diante da grande demanda reprimida por procedimentos odontológicos, contudo não observam que esta é produzida também a partir do que historicamente os serviços ofertam e de como produzem o cuidado.

O uso de protocolos pelas ESB apresenta-se como um processo mais complexo e subjetivo do que tradicionalmente compreendem gestores da saúde responsáveis pela organização do trabalho na saúde. Os trabalhadores para exercer suas atividades necessitam recorrer aos próprios julgamentos e valores, talentos e criatividade, de forma a gerir as variabilidades inerentes às situaçôes do cotidiano de trabalho. Para 
concretizarem o uso de protocolos, necessitam produzir pertencimento ao que está sendo proposto e à história da instituição na qual atuam.

A interação das ESB promovida pelo estudo permitiu uma abertura para compreender o modo como diretrizes e protocolos ditados pelas políticas de saúde bucal impulsionam e produzem as práticas discursivas profissionais. Verificou-se que ainda é precário o modo como as atividades de acolhimento \& acesso de necessidades de saúde bucal são instituídas como coletivas, evidenciando um protagonismo limitado das ESB na organização dos próprios processos de trabalho para superar os entraves que as práticas individualizadas apresentam.

O não reconhecimento da problematização dos próprios processos de trabalho como tecnologia de educação permanente que amplia competências está marcado pela demasiada separação entre gestão, educação permanente e práticas clínicas. Ainda apresenta-se escasso o debate de valores entre instituiçóes de ensino e serviços de saúde como eixo condutor do processo de estímulo à produção e inovação de um cuidado direcionado às necessidades de saúde bucal.

\section{Contribuições dos autores}

CMW trabalhou na pesquisa, na concepção do artigo, na análise e interpretação dos dados, na redação do artigo; ETR, na pesquisa na concepção do artigo, na análise dos dados e na redação do artigo; JB, na revisão crítica e na aprovação da versão a ser publicada.

\section{Direitos autorais}

Este artigo está licenciado sob a Licença Internacional Creative Commons 4.0, tipo BY (https://creativecommons.org/licenses/by/4.0/deed.pt_BR).

$(\mathrm{cc})$

\section{Referências}

1. Ministério da Saúde (BR). Secretaria de Atenção à Saúde. Departamento de Atenção Básica. Coordenação Nacional de Saúde Bucal. Diretrizes da Política Nacional de Saúde Bucal. Brasília: Ministério da Saúde; 2004.

2. Scherer CI, Scherer MDA. Avanços e desafios da saúde bucal após uma década de Programa Brasil Sorridente. Rev Saude Publica. 2015; 49(98):1-12.

3. Rocha RACP, Goes PSA. Comparação do acesso aos serviços de saúde bucal em áreas cobertas e não cobertas pela Estratégia Saúde da Família em Campina Grande, Paraíba, Brasil. Cad Saude Publica. 2008; 24(12):2871-80.

4. Corrêa GT, Celeste RK. Association between coverage by oral health teams in the family health and the increase in dental care output in Brazilian municipalities, 1999 and 2011. Cad Saude Publica. 2015; 31(12):2588-98.

5. Travassos C, Martins M. Uma revisão sobre os conceitos de acesso e utilização de serviços de saúde. Cad Saude Publica. 2004; 20 Supl 2:190-8. 
6. Neves CAB, Heckert ALC. Micropolítica do processo de acolhimento em saúde. Estud Pesqui Psicol. 2010; 10(1):151-68.

7. Souza ECF, Vilar RLA, Rocha NSPD, Uchoa AC, Rocha PM. Acesso e acolhimento na atenção básica: uma análise da percepção dos usuários e profissionais de saúde. Cad Saude Publica. 2008; 24 Supl 1:100-10.

8. Warmling CM, Marzola NR, Botazzo C. Da autonomia da boca: práticas curriculares e identidade profissional na emergência do ensino brasileiro da odontologia. Hist Cienc Saude Manguinhos. 2012; 19(1):181-95.

9. Pires FS, Botazzo C. Organização tecnológica do trabalho em saúde bucal no SUS: uma arqueologia da política nacional de saúde bucal. Saude Soc. 2015; 24(1):273-84.

10. Frazão P, Narvai PC. Sistemas de trabalho de alta cobertura na assistência odontológica na perspectiva do sistema único de saúde. São Paulo: Proj Inovações do Ensino Básico; 1993: 135-50.

11. Ministério da Saúde (BR). Secretaria-Executiva. Núcleo Técnico da Política Nacional de Humanização. HumanizaSUS Política Nacional de Humanização a humanização como eixo norteador das práticas de atenção e gestão em todas as instâncias do SUS. Brasília: Ministério da Saúde; 2004. (Série B Textos Básicos Saúde).

12. Nora CRD, Junges JR. Política de humanização na atenção básica: revisão sistemática. Rev Saude Publica. 2013; 47(6):1186-200.

13. Neves M, Giordani JMA, Ferla AA, Hugo FN. Primary care dentistry in Brazil: from prevention to comprehensive care. J Ambul Care Manage. 2017; 40 Suppl 2:35-48.

14. Harrison S. New labour, modernisation and the medical labour process. J Soc Policy. 2002; 31(3):465-85.

15. Berg M. Problems and promises of the protocol. Soc Sci Med. 1997; 44(8):1081-8.

16. May C, Rapley T, Moreira T, Finch T, Heaven B. Technogovernance: evidence, subjectivity, and the clinical encounter in primary care medicine. Soc Sci Med. 2006; 62(4):1022-30.

17. Armstrong P. Puzzling skills: feminist political economy approaches. Can Rev Sociol. 2013; 50(3):256-83.

18. Schwartz Y. Uso de si e competência. In: Schwartz Y, Durrive L. Trabalho e ergologia: conversas sobre a atividade humana. 2a ed. Niterói: Eduff; 2010.

19. Prefeitura Municipal de Porto Alegre. Secretaria Municipal de Saúde de Porto Alegre. Coordenação de Atenção Primária, Serviços Especializados e Substitutivos. Acolhimento com identificação de necessidades: guia de orientação para as unidades de saúde. Porto Alegre: Secretaria Municipal de Saúde; 2014.

20. Ramos DD, Lima MADS. Acesso e acolhimento aos usuários em uma unidade de saúde de Porto Alegre, Rio Grande do Sul, Brasil. Cad Saude Publica. 2003; 19(1):2734 .

21. Machado LX, Toassi RFC, Warmling CM. Práticas de acolhimento em saúde bucal na atenção primária à saúde. In: Bulgarelli AF, Nunes AMA, Warmling CM, Hugo FN, Frichembruder K, Lemos, et al., organizadores. Redes atenção à saúde. Porto Alegre: Rede Unida; 2016.

22. Yin RK. Estudo de caso: planejamento e métodos. 5a ed. Porto Alegre: Bookman; 2015. 
23. Warmling CM, Fajardo AP, Meyer DE, Bedos C. Práticas sociais de medicalização \& humanização no cuidado de mulheres na gestação. Cad Saude Publica. 2018; 34(4):e00009917.

24. Schwartz Y, Durrive L. Trabalho e ergologia: conversas sobre a atividade humana. 2a ed. Niterói: UFF; 2010.

25. Pezzato LM, L’abbate $S$. O uso de diários como ferramenta de intervenção da análise institucional: potencializando reflexôes no cotidiano da saúde bucal coletiva. Physis. $2011 ; 21(4): 1297-314$.

26. Hollander J, Gordon $H$. The processes of social construction in talk. Symb Interact. 2006; 29(2):183-212.

27. Ryan KE, Gandha T, Culbertson MJ, Carlson C. Focus group evidence: implications for design and analysis. Am J Eval. 2014; 35(3):328-45.

28. Foucault M. A ordem do discurso: aula inaugural no Collège de France, pronunciada em 2 de dezembro de 1970. 11a ed. São Paulo: Loyola; 2004.

29. Nascimento AC, Moysés ST, Werneck RI, Moysés SJ. Oral health in the context of primary care in Brazil. Int Dent J. 2013; 63(5):237-43.

30. Tesser CD, Norman AH. Repensando o acesso ao cuidado na estratégia saúde da família. Saude Soc. 2014; 23(3):869-83.

31. Garuzi M, Achitti MCO, Sato CA, Rocha SA, Spagnuolo RS. Acolhimento na estratégia saúde da família: revisão integrativa. Rev Panam Salud Publica. 2014; 35(2):144-9.

32. Rodrigues AAAO, Assis MMA. Oferta e demanda na atenção à saúde bucal: o processo de trabalho no programa saúde da família em Alagoinhas - Bahia. Rev Baiana Saude Publica. 2005; 29(2):273-85.

33. Tesser CD, Pezzato LM, Silva EN. Medicalização social e odontologia: possíveis aproximaçóes. Saude Soc. 2015; 24(4):1349-61.

34. Mendes-Gonçalves RB. Práticas de saúde: processos de trabalho e necessidades. In: Mendes-Gonçalves RB, Ayres JRCM, Santos L, organizadores. Saúde, sociedade e história. São Paulo: Hucitec; 2017.

35. Fracolli LA, Zoboli ELCP. Descrição e análise do acolhimento: uma contribuição para o programa de saúde da família. Rev Esc Enferm USP. 2004; 38(2):143-51.

36. Prefeitura Municipal de Porto Alegre. Secretaria Municipal de Saúde de Porto Alegre. Coordenação de Atenção Primária, Serviços Especializados e Substitutivos. Área Técnica de Saúde Bucal. Protocolo de Atenção em Saúde Bucal de Porto Alegre: organização da rede e fluxos de atendimento. Porto Alegre: Secretaria Municipal de Saúde; 2014.

37. Ministério da Saúde (BR). Secretaria de Atenção à Saúde. Departamento de Atenção Básica. Normas e manuais técnicos cadernos de atenção básica 17 saúde bucal. Brasília: Ministério da Saúde; 2008. (Série A).

38. Gomes MCP, Pinheiro R. Acolhimento e vínculo: práticas de integralidade na gestão do cuidado em saúde em grandes centros urbanos. Interface (Botucatu). 2005; 9(17):287-301.

39. Scherer MDA, Pires D, Schwartz Y. Trabalho coletivo: um desafio para a gestão em saúde. Rev Saude Publica. 2009; 43(4):721-5. 
The aim of the present study was to understand how the Oral Health Teams of Primary Health Care coordinate the competencies of user embracement and access to oral health needs in their professional practice. This was a unique and integrated qualitative case study. A script based on the competencies of different practices supported the creation of nine focus groups (sixteen surgical dentists, five assistants, seven oral health technicians and two resident surgical dentists). When implementing user embracement $\&$ access protocols, priority is still given to spontaneous and emergency user demands in dental offices. Innovative practices of user embracement and access are related to the subjective competences of workers in collective work and adjusting protocols to health realities. Continuing education programs should facilitate the discussion about values among teaching institutions and services.

Keywords: User embracement. Professional competence. Professional practice. Health services accessibility. Continuing education.

El objetivo del estudio es comprender la forma como los Equipos de Salud Bucal de Atención Primaria de la Salud articulan en el actuar profesional las competencias de acogida y de acceso de las necesidades de salud bucal. Se trata de un estudio de caso del tipo único e integrado con abordaje cualitativo. Un guion basado en el actuar en competencia apoyó la realización de nueve grupos focales (dieciséis cirujanos-dentistas, cinco auxiliares, siete técnicos de salud bucal y dos cirujanosdentistas residentes). En la implantación de protocolos de acogida y acceso persiste la priorización de demandas espontáneas y de urgencias de los usuarios al consultorio odontológico. Prácticas innovadoras de acogida y acceso se relacionan con competencias subjetivas de los trabajadores en el trabajo colectivo y en la renormalización entre protocolos y realidades de salud. Los diseños de educación permanente en salud deben propiciar el debate de valores entre instituciones de enseñanza y servicios.

Palabras clave: Acogida. Competencia profesional. Práctica profesional. Acceso a los servicios de salud. Educación permanente. 